\title{
Uma análise acerca das filosofias educacionais
}

\author{
An analysis about educational philosophies \\ Un análisis sobre filosofías educativas
}

Recebido: 03/03/2021 | Revisado: 09/03/2021 | Aceito: 12/05/2021 | Publicado: 28/05/2021

José Cândido da Silva Nóbrega

ORCID: https://orcid.org/0000-0002-0976-3763

Universidade Federal de Campina Grande, Brasil E-mail: jcandidosn@uol.com.br

Mônica Barbosa de Sousa Freitas

ORCID: https://orcid.org/0000-0001-8073-3359

Universidade Federal de Campina Grande, Brasil

E-mail: mbarbosadesousafreitas@gmail.com

Francisco das Chagas Bezerra Neto

ORCID: https://orcid.org/0000-0001-6232-4383

Universidade Federal de Campina Grande, Brasil E-mail: chagasneto237@gmail.com

Wesley Queiroz Peixoto

ORCID: https://orcid.org/0000-0001-8951-3627 Universidade Federal do Rio Grande do Norte, Brasil

E-mail: queiroz97q@gmail.com

José Marcolino Neto

ORCID: https://orcid.org/0000-0002-4988-8747

Universidade Federal de Campina Grande, Brasil E-mail: joseneto140399@gmail.com

João Paulo Borges de Queiroz

ORCID: https://orcid.org/0000-0002-8002-404X

Universidade Federal de Campina Grande, Brasil E-mail: jpb-queiroz@hotmail.com

\begin{abstract}
Resumo
O conteúdo abordado tem como fundamento precípuo analisar a filosofia educacional, sobretudo no que diz respeito às abordagens filosóficas. Nessa perspectiva, este artigo, através da pesquisa exploratória, de natureza qualitativa, método dedutivo, coleta de dado bibliográfica, procedeu-se de modo a realizar uma análise acerca das linhas filosóficas educacionais adotas atualmente pelos docentes com os estilos de ensino empregado no cotidiano da sala de aula. Não obstante, foram abordados os critérios adotados pela "PhilosophicalPreferences Assessment", que foi desenvolvida por Wiles e Bondi (2007) e adaptada por Doğanay e Sari (2003), categorizando em cinco filosofias educacionais, sendo perenismo, idealismo, realismo, experimentalismo e existencialismo. Por fim, diante da problemática exposta, buscou-se elucidar a necessidade da continuidade do estudo filosófico, pautado na promoção social e bem-estar social, traçar mecanismos capazes de preservar e garantir o direito fundamental à educação, tendo em vista os incômodos substanciais causados ao Estado Democrático de Direito pela não observância dessa garantia.
\end{abstract}

Palavras-chave: Filosofia educacional; Abordagens filosóficas; Educação.

\begin{abstract}
The approached content has as its main foundation to analyze an educational philosophy, especially with regard to philosophical approaches. In this perspective, this article, through exploratory research, of a qualitative nature, deductive method, collection of bibliographic data, proceeded in order to carry out an analysis about the educational philosophical lines currently adopted by teachers with the styles of effective teaching in the daily life of the school. classroom. Nevertheless, they were imputed to the criteria adopted by the "Evaluation of Philosophical Preferences", which was developed by Wiles and Bondi (2007) and adapted by Doğanay and Sari (2003), categorizing into five educational philosophies, being perennialism, idealism, realism, experimentalism and existentialism. Finally, in view of the exposed problem, it was sought to elucidate the need for continuity of philosophical study, based on social promotion and social well-being, to outline mechanisms capable of preserving and guaranteeing the fundamental right to education, in view of the substantial disadvantages harmed to the Democratic State of Law for non-observance of this guarantee.
\end{abstract}

Keywords: Educational philosophy; Philosophical approaches; Education. 


\section{Resumen}

El contenido abordado tiene como fundamento principal el análisis de una filosofía educativa, especialmente en lo que se refiere a enfoques filosóficos. En esta perspectiva, este artículo, a través de una investigación exploratoria, de carácter cualitativo, método deductivo, recolección de datos bibliográficos, se procedió a realizar un análisis sobre las líneas filosóficas educativas que actualmente adoptan los docentes con los estilos de enseñanza efectiva en el día a día. vida de la escuela. aula. Sin embargo, fueron imputados a los criterios adoptados por la "Evaluación de Preferencias Filosóficas", que fue desarrollada por Wiles y Bondi (2007) y adaptada por Doğanay y Sari (2003), categorizándolas en cinco filosofías educativas, siendo perennialismo, idealismo, realismo, experimentalismo y existencialismo. Finalmente, ante la problemática expuesta, se buscó dilucidar la necesidad de una continuidad del estudio filosófico, basado en la promoción social y el bienestar social, para delinear mecanismos capaces de preservar y garantizar el derecho fundamental a la educación, en vista de la desventajas sustanciales perjudicadas al Estado Democrático de Derecho por el incumplimiento de esta garantía.

Palabras clave: Filosofía educativa; Enfoques filosóficos; Educación.

\section{Introdução}

As filosofias educacionais podem ser categorizadas diferentemente em termos de critérios adotados na literatura. Quanto a uma classificação comum, eles são realizados sob quatro títulos denominados "perenismo, progressivismo, essencialismo e reconstrutivismo" (Demirel, 2005). Na forma "PhilosophicalPreferences Assessment", que foi desenvolvida por Wiles e Bondi (2007) e adaptada por Doğanay e Sari (2003), existem cinco filosofias educacionais; perenismo, idealismo, realismo, experimentalismo e existencialismo. Nessa esteira, este estudo examina as abordagens filosóficas nessas cinco categorias.

Tendo em vista a relevância do tema proposto, será realizada uma pesquisa exploratória, que tem por objetivo proporcionar uma maior familiaridade com o problema. Sem a perspectiva de esgotamento do tema, tratar-se-á, sobretudo, acerca das filosofias educacionais. Ademais, se utilizará do método de abordagem dedutivo, uma vez que se buscará os resultados a partir da análise geral até concluir de maneira particular a hipótese. Quanto à natureza da pesquisa, esta será qualitativa, buscar-se-á analisar e interpretar os institutos da Filosofia Educacional, como forma de chegar à conclusão de que é possível adotar um mecanismo capaz de assegurar uma educação efetiva.

Quanto ao método de procedimento, atribuir-se-á o método monográfico, partindo de um estudo profundo sobre a filosofia educacional, que podendo esta pesquisa ser considerada representativa de muitos outros ou mesmo de todos os casos semelhantes. Além do mais, quanto aos procedimentos técnicos, se delineará o presente estudo por meio de pesquisa bibliográfica, tendo em vista que se buscará, através da renomada doutrina e periódicos especializados.

No presente trabalho, portanto, serão apresentados alguns apontamentos acerca da filosofia educacional, e as abordagens filosóficas pautada no perenismo, idealismo, realismo, experimentalismo e existencialismo.

\section{Abordagens Filosóficas}

Os perenialistas enfatizam a formação da educação de acordo com certas realidades universais. Eles pensam que a natureza humana, os valores morais, a realidade e a verdade são fenômenos universais (Demirel, 2005). Eles afirmam que a natureza humana é perene. Os seres humanos têm a capacidade de questionar e compreender as realidades universais da natureza. O propósito da educação é educar as pessoas sensatas, treinando cuidadosamente a mente, descobrir a verdade universal e prover a conformidade com a verdade eterna, não a realidade de hoje (Ornstein, 1988). Como a verdade é a mesma em toda parte, a educação deve ser a mesma em todos os lugares também. A educação é a preparação para a vida, não uma cópia da vida. Defende-se que o ideal deve ser apresentado em ambientes educacionais, e não a própria vida real (Demirel, 2005).

Nessa esteira, pode destacar que o perenismo indica que as ciências humanas são importantes, pois esclarece os conceitos de bem, verdade e beleza (Demirel, 2005, p. 20). O currículo perenialista é centrado no assunto. O conhecimento e a 
expertise dos professores não podem ser questionados e aceitos como autoridades. Além disso, o professor deve ser o mestre de seu assunto e a instrução, e dirigir a discussão. A instrução é baseada principalmente no método socrático. O professor deve ser um modelo por meio de discurso oral, explicação e interpretação. O aluno aprenderá imitando o professor (Ornstein, 1988).

No tocante ao idealismo, pode-se afirma que a realidade está intimamente relacionada à ideia, pensamento e mente, $\mathrm{e}$ não ao poder terreno. Segundo os idealistas, a realidade é ideia, pensamento e alma. Não aceita o método científico como o único caminho para a realidade; mas assume o pensamento intuitivo tão importante quanto o método científico. Na filosofia educacional idealista, que expressa uma abordagem centrada no professor, o professor é obrigado a revelar o conhecimento embutido no subconsciente dos alunos e a ser um bom modelo moral e culturalmente. Os assuntos estão em ordem hierárquica e o Método Socrático é adotado. O professor é qualificado e bem doado; ordem, disciplina e autoridade são uma questão de fato (Ornstein, 1988).

No que tange a abordagem filosófica realista, pontua-se que para os realistas o mundo em termos de sujeitos/objetos e substâncias. As pessoas podem entender o mundo através dos sentidos e da lógica. A fonte de tudo é a natureza e formada pelas regras da natureza. De acordo com o realismo, o propósito da educação é tornar as pessoas felizes, fornecendo-lhes as melhores e mais perfeitas habilidades. Ao mesmo tempo em que ilumina os alunos nos campos do conhecimento, também visa desenvolver a mente que é a habilidade e o poder mais importantes do ser humano e encorajar o que eles querem em suas escolhas, expressando-se com um potencial perfeito e identificando suas próprias identidades (Demirel, 2005).

No realismo, a abordagem é centrada no professor, sendo que o professor é um instrutor ou educador, em vez de um cientista ou pesquisador que é um especialista em seu campo, e conhece a verdade máxima necessária sobre o campo. O professor é um instrutor profissional em termos de conhecimento especializado e habilidade instrucional (Demirel, 2005). Ele/ela fornece aos alunos para adquirir certo conhecimento e proficiência. Os estudantes devem estar prontos para aprender as coisas necessárias e estar ansiosos para fazer um esforço (Alberes, 1978).

$\mathrm{Na}$ abordagem filosófica experimentalista, pode destacar que um dos pioneiros do experimentalismo é John Locke. De acordo com Locke, a mente é como um papel branco ou uma lousa em branco na qual nada está antes do experimento e todas as fontes de conhecimento vêm da observação e dos dados em mente como resultado do uso dos sentidos. Em suma, não há conhecimento inato na mente humana e a fonte e ferramenta de todo tipo de conhecimento é o experimento (Alberes, 1978). Outro pioneiro é John Dewey. Para Dewey, pensamento e ação não podem ser separados e o pensamento é incompleto sem realização.

O pensamento básico envolve os problemas que uma pessoa encontra e resolve pelo método científico. A resolução de problemas é também um processo social como um fenômeno individual. Como o compartilhamento é mais, as oportunidades de desenvolvimento também são maiores (Alberes, 1978). O experimentalismo, que é baseado no pragmatismo, ajuda o ser humano a melhorar seu ambiente e sua adaptação ao meio ambiente. Aceita a mudança como base da realidade e assume que a educação está melhorando continuamente. A criança deve estar ativa em ambientes educacionais organizados de acordo com seus interesses. O conhecimento, que é uma ferramenta importante para obter, melhorar e regular as experiências, deve ser obtido com interação e depende dos interesses da criança. A responsabilidade do professor é orientar os alunos. A escola deve incentivar os alunos a colaborar em vez de correr em ambientes escolares democráticos; o que é mais escola é o ambiente mais apropriado para a aprendizagem (Demirel, 2005).

No tocante ao existencialismo, salienta-se que os existencialistas percebem o mundo em termos de subjetividade pessoal (Alberes, 1978). Bondade, verdade e realidade são definidas individualmente. A realidade é um mundo de existência (Heidegger, 2005), a verdade é subjetivamente escolhida e a bondade é uma questão de liberdade (Wiles \& Bondi, 2007, p. 45). O fundamento básico da filosofia existencialista é que a pessoa tem liberdade de escolha ao se definir (Alberes, 1978). Os existencialistas dão importância ao humano. 
No existencialismo, a educação é uma atividade que proporciona ao indivíduo a experiência de sucesso, fracasso, fealdade, beleza, luta e dor, sem exagerar, mas honestamente (Alberes, 1978). A educação deve permitir que uma pessoa se identifique com suas características reais. Na interação professores-alunos, a responsabilidade do professor é ajudar os alunos a aprender e se conhecerem (Wiles \& Bondi, 2007). De acordo com Alberes (1978), um bom professor existencialista não pretende treinar personalidades de cópia. Ele tenta equilibrar o conteúdo e o aluno e ser sensível aos alunos. Um professor existencialista faz um esforço para três finalidades: processar o conteúdo, estimular a mente a funcionar de forma independente e criar uma crença sobre a realidade para os alunos (Alberes, 1978). "A mudança nos ambientes escolares seria adotada como um fenômeno natural e necessário" (Wiles \& Bondi, 2007, p. 45).

\section{A Filosofia e a Educação}

$\mathrm{O}$ assunto da educação e filosofia é humano. O ponto de vista humano pode afetar todos os componentes da educação. Em outras palavras, o humano é tratado e a educação é organizada de acordo com esse ponto de vista (Alberes, 1978). O professor emprega uma filosofia educacional quando começa a pensar em conceitos e conhecimentos da natureza humana e da sociedade. A filosofia educacional é uma disciplina da filosofia que discute a educação e questiona e resolve os conceitos e práticas da educação (Wiles \& Bondi, 2007, p. 45).

A filosofia educacional ajuda o educador e os professores a compreender a educação com todos os seus aspectos. O significado e a importância das práticas educacionais só podem ser possíveis por um sistema de pensamento claro que a filosofia forneça (Sartre, 1978). Além disso, a filosofia fornece uma estrutura e uma base para organizar as configurações da escola e da sala de aula para os educadores. Isso ajuda a entender para que servem as escolas, quais assuntos são valiosos, como os alunos aprendem e quais métodos e estratégias são usados (Demirel, 2005).

Os estilos de ensino têm um papel fundamental para organizar o processo de aprendizagem e ensino como reflexo da filosofia educacional adotada pelo professor (Wiles \& Bondi, 2007). Grasha (1996) explica o processo de aprendizagem e ensino como uma interação entre alunos e professores, que define estilos de ensino como a continuidade e consistência dos comportamentos e abordagens dos professores nesse processo; e, além disso, um modelo pessoal que os requisitos, crenças e comportamentos.

\subsection{Os Estilos de Ensino}

De acordo com Wiles e Bondi (2007), os estilos de ensino são atitudes e comportamentos dos professores em relação a programas, métodos, configurações e equipamentos instrucionais. Eles definem estilos de ensino como comportamentos instrucionais que um professor exibe consistentemente no processo de ensino. Como o professor apresenta conhecimento no processo de aprendizagem e ensino, como ele interage com os alunos e seus comportamentos sobre a socialização dos alunos são todas as reflexões de seus estilos de ensino.

Como o instrumento "estilo de ensino" desenvolvido por Grasha (1996) foi utilizado nesta pesquisa, os estilos de ensino são examinados em cinco categorias:

Especialista: Ele tem a experiência e o conhecimento necessários para os alunos. Ele presta atenção para preservar seu status como uma pessoa experiente que desenvolve habilidades de seus alunos e apresenta seu conhecimento estendido. Ele está interessado em transferência de conhecimento e treinamento de melhores alunos.

Autoridade formal: Em termos de seu conhecimento e função, ele é como um professor universitário para seus alunos. Ele tem uma característica que tem suas próprias regras, expectativas e propósitos, reforça os alunos dependendo da situação e não hesita em dar feedback negativo sob quaisquer circunstâncias não desejadas. 
Pessoal: Ele acredita na instrução de exemplos pessoais, construindo um modelo básico sobre como eles devem ser pensados e se comportar. Ele incentiva os alunos a seguir o seu caminho, supervisioná-los sobre o que devem fazer, orienta e administra.

Facilitador: Ele enfatiza a relação professor-aluno como uma característica pessoal muito natural. Sua orientação e gerenciamento de curso é fazer perguntas, para desenvolver escolhas, para apresentar alternativas, para incentivar os alunos a desenvolver os critérios científicos que eles construíram. Seu principal objetivo é desenvolver o desempenho dos alunos, que é por iniciativa e responsabilidade em suas atividades pessoais.

Delegador: Ele está interessado em melhorar a capacidade dos alunos, fazendo sua responsabilidade de forma independente. Nos cursos de professores que possuem este estilo, os alunos estudam de forma independente em projetos ou como parte de equipes independentes. O professor interfere quando os alunos perguntam como uma fonte. O estilo de ensino refere-se a propriedades distintas que são consistentes no tempo e transferidas de situação para situação (Fischer, 1979). De acordo com Heimlich e Norland (1994), o estilo de ensino inclui práticas filosóficas nas quais existem atitudes, valores, crenças, ensino e todos os elementos na mudança dos estudantes (FRIES, 2012). Fritz (2008) citou Kauchak e Eggen (2011) e Elias e Merrium (1995) que a filosofia educacional fornece uma estrutura para os professores pensarem em uma variedade de ideias, crenças, ações e assuntos educacionais que os orientam.

A Filosofia educacional afetaria os papéis dos professores e alunos na sala de aula, como o currículo é desenvolvido e avaliado, quais métodos e técnicas serão utilizados e o fator de crenças educacionais dos professores na sociedade (Fritz, 2008). A filosofia empreendida determina que a visão para o sistema humano e educacional é organizada de acordo com essa visão. Para Livingston (2001) cada professor de sala de aula tem visões diferentes sobre a estrutura das instalações educacionais fornecidas para a escola e os estudantes. Dessa forma, todo professor tem uma filosofia educacional porque “objetivos, comportamentos, conteúdo, processo de aprendizagem e avaliação devem ser organizados de acordo com os critérios da filosofia adotada" (Ediger, 2000, p. 82).

\section{Considerações Finais}

Ante todo o exposto, percebe-se a relevância do estudo das filosofias educacionais, como forma de impulsionar e aprimorar a educação em âmbito internacional e nacional.

Além disso, vislumbra-se as características pertinentes as cincos categorias da filosofia educacional, sendo o perenismo, idealismo, realismo, experimentalismo e existencialismo.

Dessa maneira, como forma de assegurar e aprimorar, de forma eficaz, o direito fundamental à educação, acreditamos que investigações como esta devem ser prosseguidas. Sendo assim, como sugestão para continuidade de discussões nesse sentido, analisar, à luz dos estudos tradicionais e recentes, de que modo as abordagens filosóficas tratam acerca da educação, contribuirá para o fortalecimento e planejamento de estratégias, assim como desenhar e formular novos e mais efetivos caminhos em direção à efetivação do direito fundamental à educação.

\section{Referências}

Alberes, R. (1978). Sartre. Fontanella.

Demirel, O. (2005). Egitimde Yeni Yönelimler. Pegem A Yayincilik.

Doğanay, A., \& Sari, M. (2003). İlköğretim öğretmenlerinin sahip olduklari ĕgitim felsefelerine ilişkin algilarinin değerlendirilmesi “Öğretmenlerin ĕ̆itim felsefeleri". Türk Eğitim Bilimleri Dergisi 1(3).

Ediger, M. (2000). Philosophy perspectives in teaching social studies. J. Instructional Psychology, https://www.questia.com/library/journal/1G1-63365165/ adresinden alinmiştir. 
Research, Society and Development, v. 10, n. 6, e22510613519, 2021

(CC BY 4.0) | ISSN 2525-3409 | DOI: http://dx.doi.org/10.33448/rsd-v10i6.13519

Elias, J. L., \& Merriam, S. B. (1995). Philosophical foundations of adult education. (2nd ed.). Krieger Publishing Company.

Fischer, B. B., \& Fischer, L. (1979). Styles in teaching and learning. Educ. Leadership, 36(4).

Fries, C. H. (2012). Teaching style preferences and educational philosophy of teacher education faculty at a state university. (Ph.D. dissertation) Oklahoma State University.

Fritz, A. (2008). Educational philosophies and teaching styles of oklahoma elementary public school teachers of english language learners. (Ph.D. dissertation) Oklahoma State University.

Heimlich, J., \& Norland, E. (1994). Developing teaching style in adult education. Jossey-Bass.

Kauchak, D. \& Eggen, P. (2011). Introduction to teaching: Becoming a professional (4th ed.). Pearson Education, Inc.

Livingston, M. J., Mcclain, B. R., \& Despain, B. C. (2001). Assessing the consistency between teachers' philosophies and educational goals. Goals and Philosophical Educ. 116(1):126.

Ornstein, C. A., \& Hunkins, F. P. (1988). Curriculum: Foundations. Principles and Issues.

Wiles, J., \& Bondi, J. (2007). Curriculum Development a Guide to Practice. Upper Saddle River: Pearson Printice Hall. 